\title{
POST CAESAREAN SCAR ENDOMETRIOSIS - A RARE DISEASE ENTITY
}

Manohar R1, Kavyashree G², Shivakumar $\mathrm{S}^{3}$

\section{HOW TO CITE THIS ARTICLE:}

Manohar R, Kavyashree G, Shivakumar S. "Post caesarean scar endometriosis - a rare disease entity". Journal of Evolution of Medical and Dental Sciences 2013; Vol2, Issue 33, August 19; Page: 6215-6218.

ABSTRACT: Endometriosis is a common gynaecological condition. It can pose a diagnostic dilemma when presented as endometriosis in the scar. This is a rare disease entity. We discuss a case of abdominal wall endometriosis following caesarean section.

INTRODUCTION: Endometriosis is defined as the presence and proliferation of the endometrium outside the uterine cavity, commonest site being the pelvis.

The actual incidence of abdominal wall scar endometriosis following hysterotomy is 1.08$2 \%$, whereas after caesarean section the incidence is around 0.03 to $0.4 \%$.

The most common site is caesarean section scar. Endometriosis, in patients with scars, is more common in the abdominal skin and subcutaneous tissue compared to muscle and fascia.

Endometriosis involving only the rectus muscle and sheath is very rare.

CASE PRESENTATION (Informed consent of the patient and ethical committee has been informed) Mrs. Xx 26 years P1L1 who underwent LSCS ( indication - FETAL DISTRESS) two years back presented with complaints of pain, and swelling at the surgical scar site since 4 months which aggravated at the onset of menstruation and used to be relieved as menstruation stopped.

On examination: P/A - a nodular mass, measuring $2 \mathrm{~cm}$ x $1.5 \mathrm{~cm}$, firm in consistency with restricted mobility, tender to palpate was present on the right side of the Pfannenstiel scar.

\section{INVESTIGATIONS:}

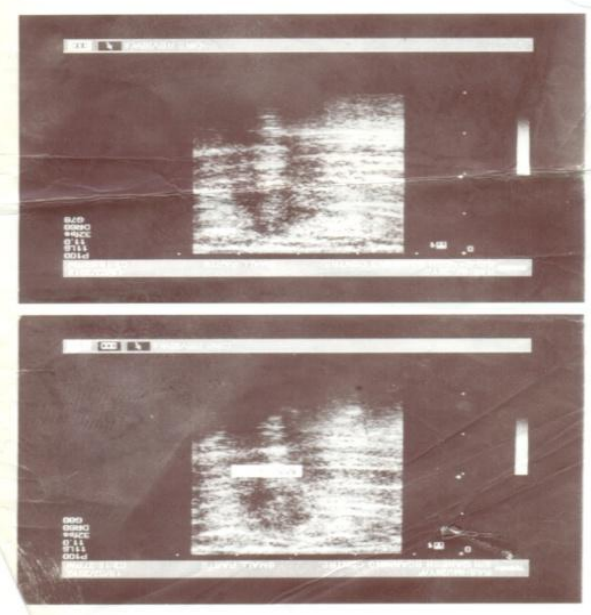

ABDOMINO PELVIC USG- revealed an irregular hypo echoic mass measuring $1.4 \mathrm{x} \quad 1.3 \mathrm{~cm}$ seen in the parietal wall of hypo gastric region within the incision. 


\section{CASE REPORT}

\section{FNAC OF SWELLING IN THE SURGICAL SCAR}

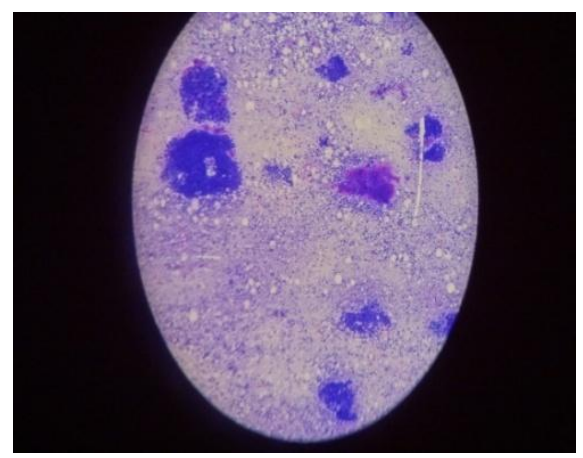

H \& E stain

Smear shows a cellular aspirate composed of many clusters of benign appearing endometrial glandular epithelial cells which are tall columnar along with many spindle cells. Few polymorphs and macrophages with karyorehectic debris are seen.

IMPRESSION: Features are suggestive of ENDOMETRIOSIS

\section{TREATMENT:}

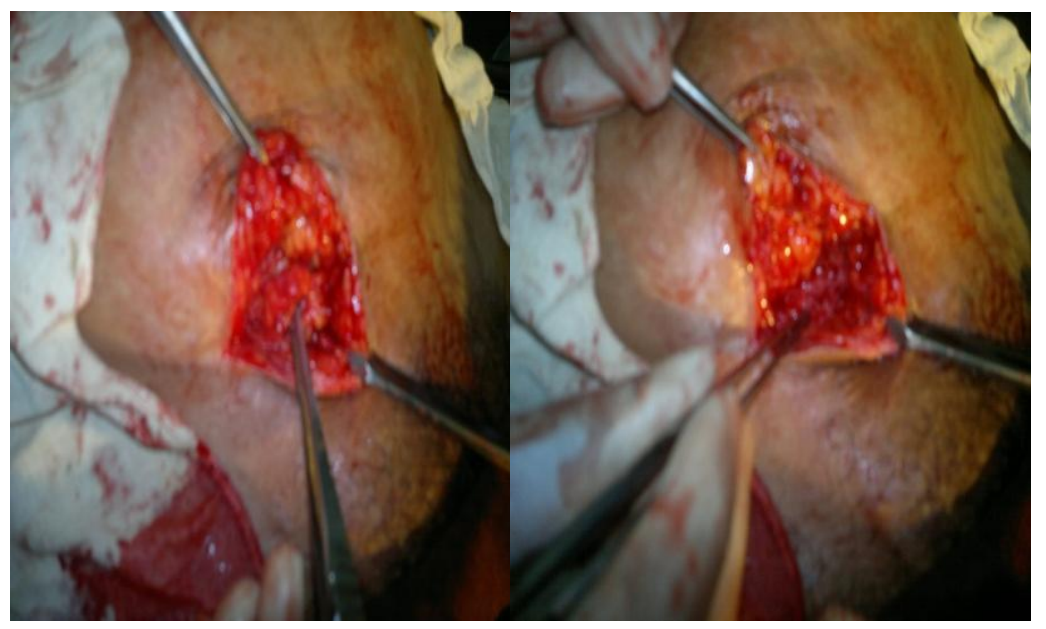

Under IV sedation, wide excision biopsy with normal surrounding tissue about $1 \mathrm{~cm}$ was done under local anaesthesia and sent for histopathological examination.

INTRA OPERATIVE findings - grayish white mass, firm in consistency adherent to rectus sheath was present which is a rare entity.

Intra operative injection of cefotaxime $1 \mathrm{gm}$ IV was given half an hour before the surgery and the patient was put on analgesics, for 3 days post operatively. The patient was on follow up for 1 year and is asymptomatic now. 


\section{HISTOPATHOLOGY:}

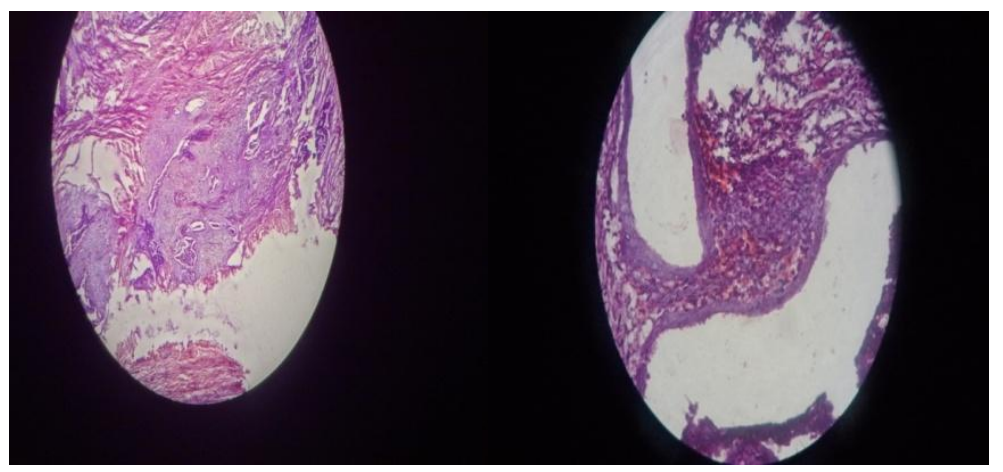

Low power $10 \mathrm{X}$
High power $45 \mathrm{X}$
H \&E stain

Excision biopsy showing fibro fatty tissue with many endometrial glands, surrounded by stroma. Foci of haemorrhage and oedema in the stroma are seen.

IMPRESSION: features are suggestive of ENDOMETRIOSIS - CAESAREAN SCAR

DISCUSSION: Endometriosis is the presence of functioning endometrial tissue outside the uterine cavity, whereas endometrioma is a well-circumscribed mass. Scar endometriomas are believed to be the result of direct inoculation of the abdominal fascia or subcutaneous tissue with endometrial cells during surgical intervention and subsequently stimulated by estrogen to produce endometriomas. This theory is convincingly demonstrated by experiments in which normal menstrual effluent transplanted to the abdominal wall resulted in subcutaneous endometriosis. In clinical practice, its occurrence has been well documented in incisions of any type where there has been possible contact with endometrial tissue, including episiotomy, hysterotomy, ectopic pregnancy, laparoscopy, tubal ligation, and cesarean section. Time interval between operation and presentation has varied from 3 months to 10 years in different series.

Scar endometriosis is rare and difficult to diagnose. It is often misdiagnosed as stitch granuloma, lipoma, abscess, cyst, incisional hernia, desmoid tumor.

The treatment of choice is always total wide excision of the lesion, which prevents recurrence. Medical treatment like Progestogens, Oral contraceptive pills, Leuprolide acetate and Danazol provides only partial relief in symptoms.

CONCLUSION: A high index of suspicion is recommended when a woman presents with cyclical pain and a post operative abdominal mass at the surgical site especially in post caesarean cases.

When the diagnosis is made on clinical grounds, USG and FNAC are indicated towards better diagnostic approach(3) CT and MRI may be of little benefit in diagnosing scar endometriosis.

Thus, the lack of awareness makes the preoperative diagnosis unnoticed. 


\section{REFERENCES:}

1. Agarwal A, Fong Y F Cutaneous endometriosis Singapore Med J 2008; 49(9):704-709.

2. Ashim K Lahiri, Kiran Sharma and Naser Busiri Endometriosis of the uterine caesarean section scar: A case report Indian journal of radiology and imaging February 2008 66-68.

3. Sarwat Ara, Anees Fatima, Mehmood Aleem, Case Report Scar endometriosis - A Rare Disease Occurrence, A.P.M.C Vol:3 no.2 July-December 2009. 162-164

4. Subrata K, Chatterjee, Scar endometriosis: A clinicopathologic study of 17 cases, obstetrics and gynaecology,vol.56,no.1,july 1980,81-84

5. Leite GKC, Carvalho LFP, Korkes H, Guazzelli TF, Kenj G, Viana AT, Scar endometrioma following obsteric surgical incisions : retrospective study on 33 cases and review of the literature, Sao Paulo Med J 2009,271-275.

\section{AUTHORS:}

1. Manohar R.

2. Kavyashree G.

3. Shivakumar $\mathrm{S}$.

\section{PARTICULARS OF CONTRIBUTORS:}

1. Assistant Professor, Department of Obstetrics and Gynaecology, Mandya Institute of Medical Sciences, Mandya.

2. Associate Professor, Department of Obstetrics and Gynaecology, Mandya Institute of Medical Sciences, Mandya.

3. Professor and HOD, Department of Pathology, Mandya Institute of Medical Sciences, Mandya.

\section{NAME ADDRESS EMAIL ID OF THE} CORRESPONDING AUTHOR:

Dr. Manohar R, Assistant Professor, Department of Obstetrics and Gynaecology, Mandya Institute of Medical Sciences, Mandya. Email-manoharrangaswamy@gmail.com

Date of Submission: 02/08/2013. Date of Peer Review: 03/08/2013. Date of Acceptance: 10/08/2013. Date of Publishing: 14/08/2013 